\title{
A Microstructure for in situ Determination of Residual Strain
}

\author{
Chi Shiang Pan and Wensyang Hsu
}

\begin{abstract}
This work presents a new strain sensor with a compact structure. The strain sensor comprises of a pair of cantilever beams with different lengths connected by a short tip. The residual strain causes two beams to deflect each other, thereby magnifying the deflection, which is measured by the tip. The displacement is independent of both Young's modulus and the film's thickness. An analytical model is derived to relate the measured displacement to residual strain. Finite-element modeling is also used to analyze the model. This work also thoroughly considers other factors that influence the designs and the implicit limitations of the strain sensors. Experimental results with an $\mathrm{SiO}_{2}$ film as well as undoped LPCVD polysilicon films are used to demonstrate the effectiveness of the proposed structure. [250]
\end{abstract}

Index Terms - Residual strain, thin film.

\section{INTRODUCTION}

$\mathbf{M}$ EASURING stresses in thin films is vital to designing fabrication processes and actual devices. A variety of methods have been developed to measure residual stresses in thin films [1]-[10]. A conventional approach involves using microstructures for passive strain sensing. These are basically suspended microstructures that deform under residual stresses. These microstructures are fabricated in situ along with the active devices on the same chip. One type of the passive strain sensors utilizes the buckling technique. The technique is based on proof structures in which a beam's maximum length remains unbuckled under a compressive strain [1]. Previous efforts have modified these proof structures as ring or diamond structures for measuring tensile strain [2]-[4]. However, there are some disadvantages in using the buckling technique. For instance, an entire array of the microstructures is needed, implying that: 1) they occupy a large area and 2) the difference in the beam's length in the array determines the strain resolution. Another disadvantage is that the boundary condition can be a factor determining strain accurately.

Other types use only one microstructure. The so-called Tand $\mathrm{H}$-shaped microstructures provide the displacement of a junction between wide and narrow beams [5], [6]. However, such structures yield extremely small displacements, thereby making an accurate measurement difficult. Long cantilever beams to magnify the displacement have also been proposed. One kind is a rotating pointer comprised of two opposed test

Manuscript received January 29, 1997; revised November 27, 1997. This work was supported by the National Science Council of the Republic of China under Contract NSC86-2221-E009-042. Subject Editor, D. Cho.

The authors are with the Department of Mechanical Engineering, National Chiao Tung University, Hsin Chu 30050, Taiwan, R.O.C.

Publisher Item Identifier S 1057-7157(99)02060-0.

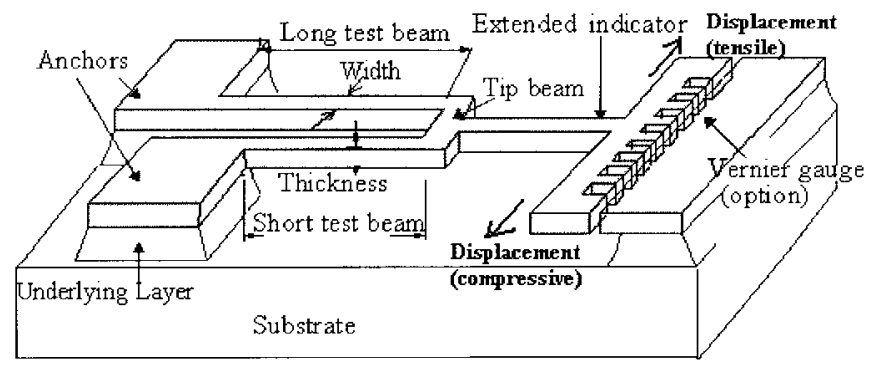

Fig. 1. Schematic diagram of the strain sensor.

beams and a third beam as the gauge [7], [8]. The strain of two test beams is converted into the rotation of the third beam, and then the stress level in the two test beams is deduced by measuring the free end movement of the third beam. Accurate measurements require a long third beam, but this is limited due to the out-of plane deformation. In addition, the stiffness and stress concentration of the turning points can significantly influence the movement. Therefore, the strain sensor requires a correction factor for different widths of the turning points. Another kind of strain sensor uses an indicator beam to magnify the small displacement of a long test beam through a sloped beam [9], but the residual stress and the stiffness of the sloped beam affect on the measurement. Gianchandani et al. [10] designed a passive strain sensor that utilized a pair of bent beams with an apex at the mid-points. The bent beams magnify deformations, similar to a parallelogram mechanism. The magnification of the motion is attributed to the tilt angle of the bent beams, which is highly sensitive to the variations of the tilt angle. The strain sensor performance depends on properly designing the tilt angle and the symmetry of the bent beams.

In this paper, we present a new structure for a strain sensor, which has a significantly small structural size but a large magnification factor. The proposed sensor requires no correction factor. An analytical model is also derived and characterized to relate the measured displacement to residual strain. Finite element modeling is used to support the analytical model, and experimental results with $\mathrm{SiO}_{2}$ and polysilicon films are used to demonstrate the sensor performance, which is compared to the data from other strain sensors.

\section{OPERATING PRINCIPLES}

Fig. 1 schematically depicts the strain sensor. The sensor consists of a pair of cantilever beams with different lengths connected by a short tip beam. Two cantilever beams are designed as test beams and the tip beam acts as an indicator. 
(a)
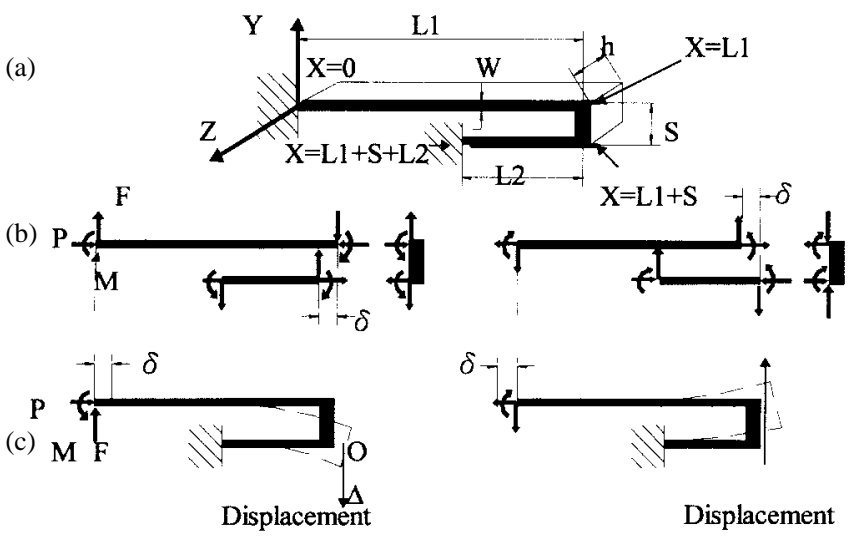

(Compressive strain)

(Tensile strain)

Fig. 2. (a)-(c) The analytical models.

The difference between the two test beams with respect to elongation or contraction due to residual strain after removing the underlying layer causes the deflection of two beams. This deflection can also be magnified by an extended indicator beam. A vernier gauge located at free end of the indicator beam can be used to quantify the deflection.

\section{ANALYTICAL MODELING AND Finite-ELEMENT MODELING (FEM)}

\section{A. Analytical Modeling}

Fig. 2 displays the analytical models of the strain sensor. In Fig. 2(a) the parameters $L_{1}$ and $L_{2}$ represent the lengths of long test beam and short test beam, respectively. In addition, $W$ and $h$ denote the width and thickness of two beams, respectively. Free ends of two cantilever beams are connected by a rigid beam with a length significantly smaller than two cantilever beams. Where $S$ denotes the distance (or gap) between center lines of the two beams. When the strain is released after removing the underlying layer, the difference between two beams with respect to elongation is denoted by $\delta$. Meanwhile, a reactive bending moment $M$, an axial force $P$, and a transverse force $F$ are induced at the boundary, as shown in Fig. 2(b). Therefore, the system can be considered as two connected beams subjected to a bending moment, an axial force, and a transverse force at the fixed end of long test beam to have the difference of the elongation $\delta$, as shown in Fig. 2(c). It can be found that

$$
\delta=L_{1} \cdot \varepsilon_{1}-L_{2} \cdot \varepsilon_{2}
$$

where the strain $\varepsilon_{1}$ in the long test beam is obtained as the subtraction of the strain due to the residual strain $\varepsilon$, and the
TABLE I

THe Formulas FOR COEFFiCIENTS IN (3)-(5)

\begin{tabular}{c|c|c}
\hline$a_{1}=\cdot\left(\mathrm{L}_{1}+\mathrm{L}_{2}\right) \cdot \mathrm{I} / \mathrm{Ab}+$ & $\mathrm{a}_{2}=1 / 2 \cdot \mathrm{S}^{2} \cdot \mathrm{L}_{1}+\mathrm{S} \cdot \mathrm{L}_{1} \cdot \mathrm{L}_{2}-$ & $\mathrm{a}_{3}=1 / 2 \cdot \mathrm{S}^{2}+\mathrm{S} \cdot \mathrm{L}_{2}$ \\
$\mathrm{I} / 3 \cdot \mathrm{S}^{3}+\mathrm{S}^{2} \cdot \mathrm{L}_{2}$ & $1 / 2 \cdot \mathrm{S} \cdot \mathrm{L}_{2}{ }^{2}$ & \\
$=1 / 12\left(\mathrm{~L}_{1}+\mathrm{L}_{2}\right) \cdot \mathrm{w}^{2}+$ & & \\
$1 / 3 \cdot \mathrm{S}^{3}+\mathrm{S}^{2} \cdot \mathrm{L}_{2}$ & & \\
where I $=1 / 12 \mathrm{~h} \mathrm{w}{ }^{3}$ & & \\
$\mathrm{Ab}=\mathrm{h} \mathrm{w}$ & & \\
\hline $\mathrm{b}_{1}=1 / 2 \cdot \mathrm{S}^{2} \cdot \mathrm{L}_{1}+\mathrm{S} \cdot \mathrm{L}_{1} \cdot \mathrm{L}_{2}-$ & $\mathrm{b}_{2}=1 / 3 \cdot \mathrm{L}_{1}{ }^{3}+\mathrm{L}_{2} \cdot \mathrm{L}_{1}{ }^{2}-$ & $\mathrm{b}_{3}=1 / 2 \cdot \mathrm{L}_{1}{ }^{2}+\mathrm{L}_{1} \cdot \mathrm{L}_{2}-1 / 2 \cdot \mathrm{L}_{2}{ }^{2}$ \\
$1 / 2 \cdot \mathrm{S} \cdot \mathrm{L}_{2}{ }^{2}$ & $\mathrm{~L}_{1} \cdot \mathrm{L}_{2}{ }^{2}+1 / 3 \cdot \mathrm{L}_{2}{ }^{3}+\mathrm{S} \cdot \mathrm{L}_{1}{ }^{2}$ & $+\mathrm{S} \cdot \mathrm{L}_{1}$ \\
\hline $\mathrm{c}_{1}=1 / 2 \cdot \mathrm{S}^{2}+\mathrm{S} \cdot \mathrm{L}_{2}$ & $\mathrm{c}_{2}=1 / 2 \cdot \mathrm{L}_{1}{ }^{2}+\mathrm{L}_{1} \cdot \mathrm{L}_{2}-1 / 2 \cdot \mathrm{L}_{2}{ }^{2}$ & $\mathrm{c}_{3}=\mathrm{L}_{1}+\mathrm{L}_{2}+\mathrm{S}$ \\
& $+\mathrm{S} \cdot \mathrm{L}_{1}$ & \\
\hline
\end{tabular}

strain due to the axial force $P, P / E A_{b}$, thus $\varepsilon_{1}=\varepsilon-P / E A_{b}$. Similarly, the strain in the short test beam, $\varepsilon_{2}$, is $\varepsilon+P / E A_{b}$. Where $E$ denotes the Young's modulus and $A_{b}$ represents the area of the cross section of the beams. Thus,

$$
\delta=\varepsilon \cdot\left(L_{1}-L_{2}\right)-\left(L_{1}+L_{2}\right) \cdot P /\left(E \cdot A_{b}\right) .
$$

If the strain sensor is in a compressive state, the values of the residual strain $\varepsilon$ and the axial force $P$ are positive. For a reverse situation, both values are negative in tensile state.

By unit-load method [11], the following equations can be derived:

$$
\begin{aligned}
E \cdot I \cdot \varepsilon \cdot\left(L_{1}-L_{2}\right) & =a_{1} \cdot P+b_{1} \cdot F+c_{1} \cdot M \\
0 & =a_{2} \cdot P+b_{2} \cdot F+c_{2} \cdot M \\
0 & =a_{3} \cdot P+b_{3} \cdot F+c_{3} \cdot M
\end{aligned}
$$

where the formula for coefficients in (3)-(5) are listed in Table I.

Then, by solving the above three equations, the values of axial force $P$, transverse force $F$, and bending moment $M$ can be found. For determining the displacement of the tip, a dummy unit force at tip point $O$ is applied, as shown in Fig. 2(c). In compressive state, the displacement of the point $O, \Delta$, can be expressed as

$$
\begin{aligned}
\Delta= & {\left[\left(1 / 2 \cdot S \cdot L_{2}^{2}\right) \cdot P+\left(1 / 2 \cdot L_{1} \cdot L_{2}^{2}-1 / 3 \cdot L_{2}^{3}\right) \cdot F\right.} \\
& \left.+\left(1 / 2 \cdot L_{2}^{2}\right) \cdot M\right] / E I
\end{aligned}
$$

From (3) to (6), $\varepsilon$ can be expressed as

$$
\varepsilon=\gamma \cdot \Delta
$$

where (8), shown at the bottom of the page.

Appendix A presents detailed derivation for (3)-(8). According to (8) and Table I, Young's modulus of the structure and the thickness of the beams do not influence the displacement of the tip at all, since both factors are eliminated in

$$
\gamma=\frac{2 \cdot\left|\begin{array}{lll}
a_{1} & b_{1} & c_{1} \\
a_{2} & b_{2} & c_{2} \\
a_{3} & b_{3} & c_{3}
\end{array}\right|}{\left(L_{1}\right) \cdot L_{2}^{2} \cdot\left[S \cdot\left|\begin{array}{ll}
b_{2} & c_{2} \\
b_{3} & c_{3}
\end{array}\right|-\left(L_{1}-\frac{2}{3} \cdot L_{2}\right) \cdot\left|\begin{array}{ll}
a_{2} & c_{2} \\
a_{3} & c_{3}
\end{array}\right|+\left|\begin{array}{ll}
a_{2} & b_{2} \\
a_{3} & b_{3}
\end{array}\right|\right]}
$$




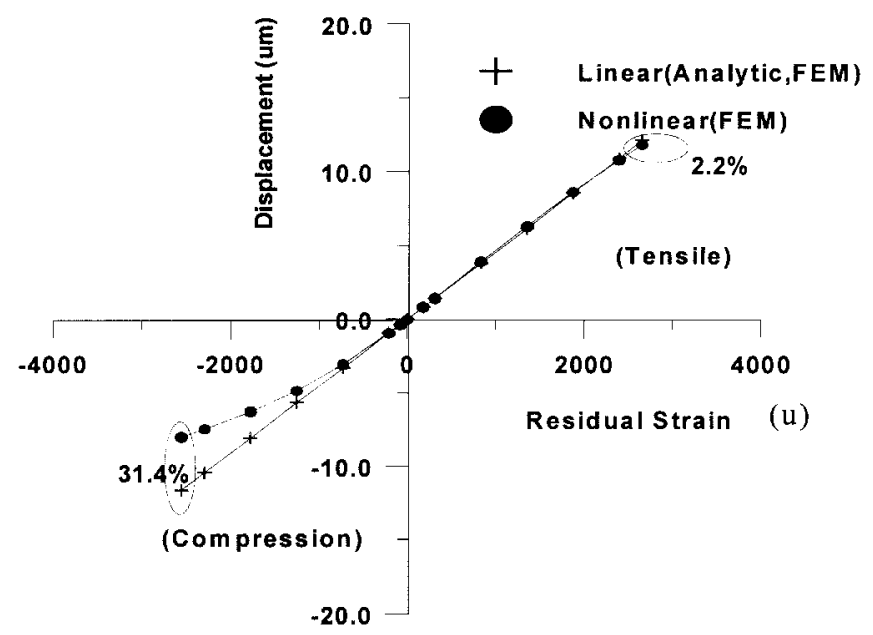

Fig. 3. Comparison of the displacements obtained by analytical modeling and FEM. $\left(L_{1}=200 \mu \mathrm{m}, L_{2}=100 \mu \mathrm{m}, h=2 \mu \mathrm{m}, w=2 \mu \mathrm{m}\right.$, $S=3 \mu \mathrm{m}$.)

the (8). The conversion factor $\gamma$ is related to geometrical parameters of the structure, including $L_{1}, L_{2}, w$, and $S$ only. The optimal design of the structure for a higher magnification factor, against buckling and without out-of-plane deformation can be obtained further. Increasing the gap distance seriously reduces the displacement. Our preliminary investigation reveals that the maximum displacement can be achieved when $L_{2} / L_{1}$ is near to 0.5 . The optimized gap distance $S$ is around 1-3 $\mu \mathrm{m}$.

\section{B. FEM}

This work employs a commercial finite-element code ANSYS 5.2 not only to perform strain-displacement analysis of the strain sensor, but also to support the analytical results. Strain is introduced in the model by applying uniform temperature change along the beams. Fig. 3 compares the displacements obtained by the analytical model with the FEM. This comparison demonstrates that the analytical approach is valid under linear behavior. Nonlinear behavior under largedeformation theory is obtained by FEM alone. Fig. 3 indicates that the strain sensor shows nonlinear behavior at larger compressive strain levels. However, we can employ the proper dimensions of the strain sensors to meet the specification.

\section{Characterization of the Strain Sensor}

\section{A. Buckling Criteria}

The models in Fig. 4(a) and (b) have simplified the device by representing it as an angled pinned-pinned bridge if the vertical buckling happened, and as an angled clamped-clamped bridge if the horizontal buckling happened [12]. Thus, the axial forces that cause buckling are

$$
\begin{array}{ll}
P_{\mathrm{vcrit}}=\frac{\pi^{2} E I_{c}}{L^{2}}, & \text { for vertical buckling } \\
P_{\mathrm{hcrit}}=\frac{4 \pi^{2} E I_{c}}{L^{2}}, & \text { for horizontal buckling }
\end{array}
$$

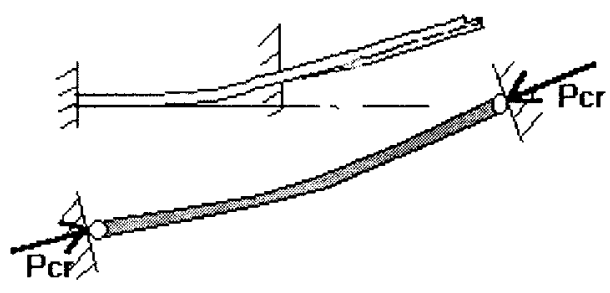

(a)

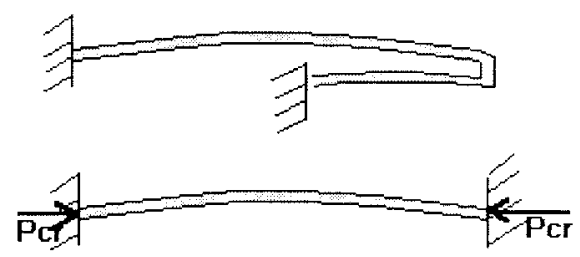

(b)

Fig. 4. (a) Side view of the vertical buckled cantilever and its equivalent pinned-pinned model. (b) Top view of the horizontal buckled cantilever and its equivalent clamped-clamped model.

where

$$
\begin{aligned}
& L=L 1 \text { compressive residual stress; } \\
& L=L 2 \text { tensile residual stress; } \\
& I c=1 / 12 h w^{3} \text { horizontal buckling; } \\
& I c=1 / 12 w h^{3} \text { vertical buckling. }
\end{aligned}
$$

Thus, the criteria of the residual strain $\varepsilon$ without causing buckling can be found as

$$
\begin{gathered}
\varepsilon \leq \frac{\pi^{2} \cdot h^{2} \cdot\left|\begin{array}{lll}
a_{1} & b_{1} & c_{1} \\
a_{2} & b_{2} & c_{2} \\
a_{3} & b_{3} & c_{3}
\end{array}\right|}{L^{2} \cdot w^{2} \cdot\left(L_{1}-L_{2}\right) \cdot\left|\begin{array}{cc}
b_{2} * c_{2} \\
b_{3} & c_{3}
\end{array}\right|} \\
\text { for vertical buckling } \\
\varepsilon \leq \frac{4 \pi^{2} \cdot\left|\begin{array}{lll}
a_{1} & b_{1} & c_{1} \\
a_{2} & b_{2} & c_{2} \\
a_{3} & b_{3} & c_{3}
\end{array}\right|}{L^{2} \cdot\left(L_{1}-L_{2}\right) \cdot\left|\begin{array}{ll}
b_{2} & c_{2} \\
b_{3} & c_{3}
\end{array}\right|} \\
\text { for horizontal buckling. }
\end{gathered}
$$

According to (11) and (12), vertical buckling is more critical than horizontal buckling unless $h$ markedly exceeds $w$. For example, Fig. 5(a) and (b) presents the critical strains for the variations of short beam length $(L 2)$ for horizontal and vertical buckling, respectively. Hence, different dimensions of the strain sensors can be made for various strain ranges.

\section{B. Side Wall Effect}

Nonvertical side wall definitely influences the accuracy of the model. Assumed herein that the function of side wall profile is $f(x)=h(x / b)^{n}$, as depicted in Fig. 6, where $b$ denotes width variation at the bottom of the side wall and $n$ represents a side wall profile factor. When the side wall is vertical, $b$ is zero and $x$ is also equal to zero. Next, the cross-section area $\left(A_{n}\right)$ and moment of inertia $\left(I_{n}\right)$ are derived 


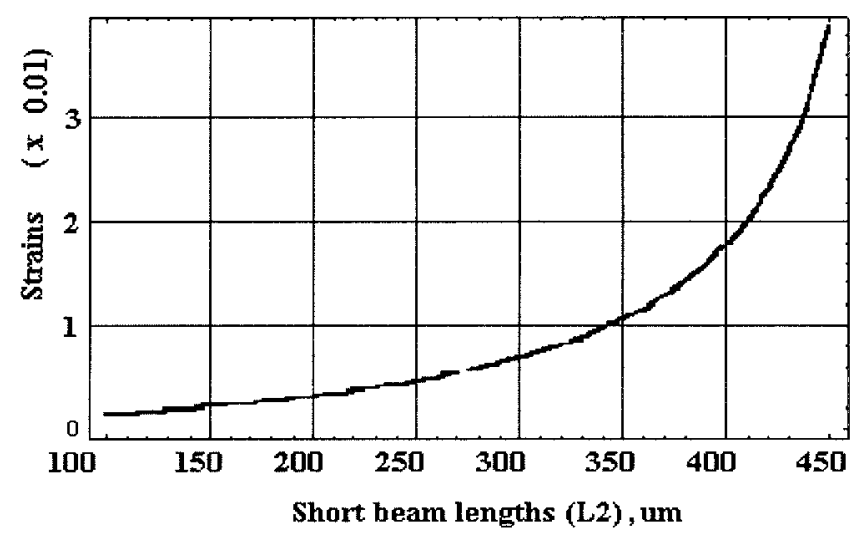

(a)

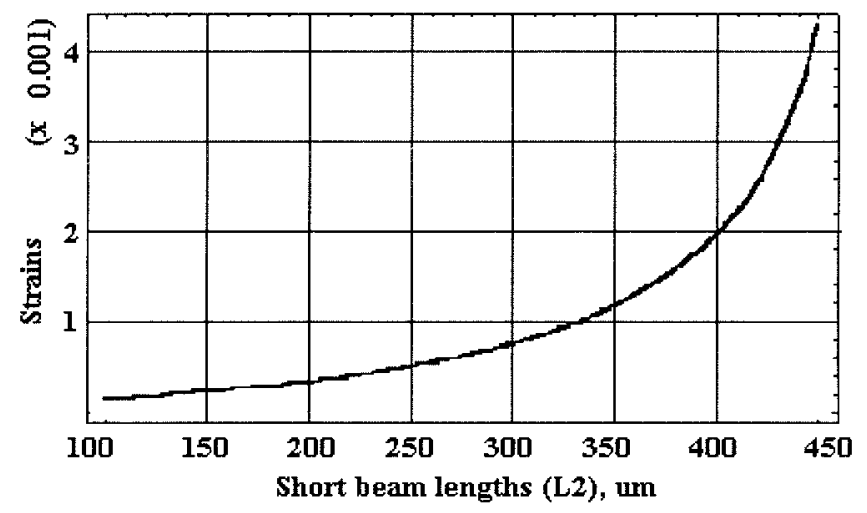

(b)

Fig. 5. Critical strains (a) for horizontal and (b) for vertical buckling with the variations in short beam length $\left(L_{2}\right)$, where $L_{1}=500 \mu \mathrm{m}, w=3 \mu \mathrm{m}$, $h=2 \mu \mathrm{m}$, and $S=7 \mu \mathrm{m}$.

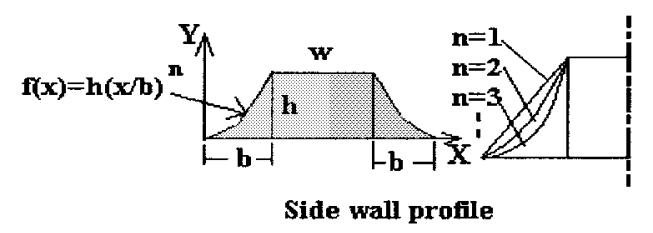

Fig. 6. Side wall profile function of a beam far from vertical.

as

$$
\begin{aligned}
A_{n} & =\frac{h(2 b+w(n+1))}{n+1} \\
I_{n} & =\frac{h w^{3}}{12}+2\left[\frac{h b^{3}}{n+3}+\frac{b h(2 b+w)(2 w+n(w-2 b))}{4(n+1)(n+2)}\right]
\end{aligned}
$$

where $A_{n}$ and $I_{n}$ will replace of the cross-section area $\left(A_{b}\right)$ and moment of inertia $(I)$ in (2) and (3) if the side wall is far from vertical. According to the analytical modeling, residual strain $\varepsilon$ is expressed as a function of displacement $\Delta$ by (7), $\varepsilon=\gamma \cdot \Delta$, where $\gamma$ is given by (8). According to Table I and (8), only coefficient $a_{1}$ is related to $I_{n}$ and $A_{n}$. Figs. 7 and 8 compare various nonvertical side wall conditions with vertical side wall condition. In our fabrication result, the thickness (h) of the strain sensor is around $2 \mu \mathrm{m}$, the width $(w)$ is around 2-4 $\mu \mathrm{m}$, and the gap $(S)$ is around 6-7 $\mu \mathrm{m}$. The side walls generally have a $5-10 \%$ width variation in the vertical

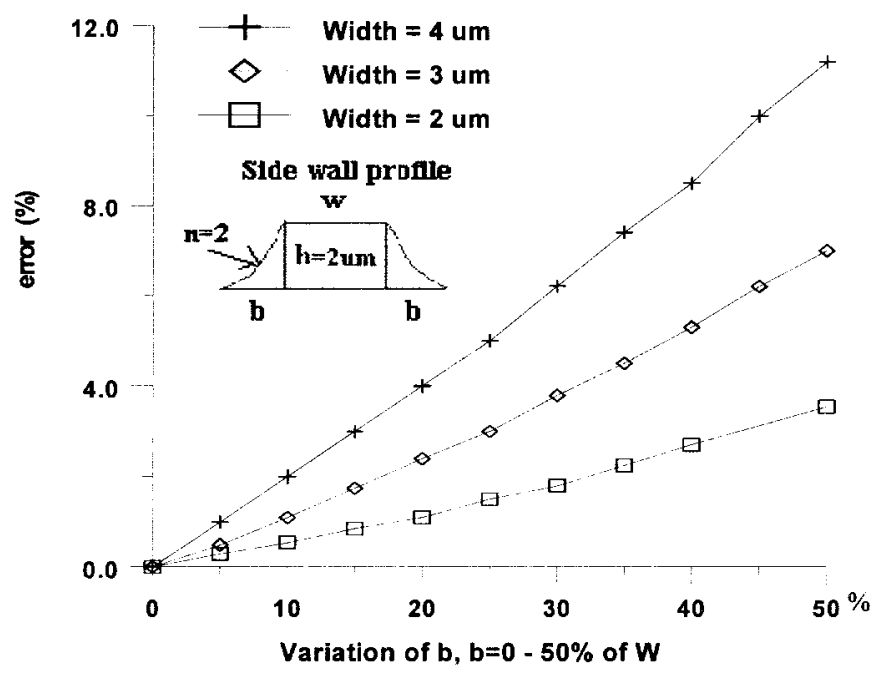

Fig. 7. Deviation of the calculated strain between vertical side wall and nonvertical side wall for width variation.

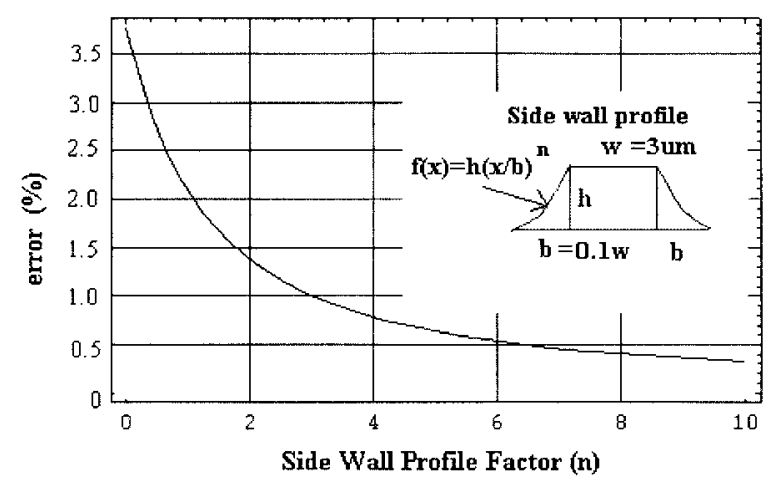

Fig. 8. The effect of side wall profile factor $(n)$, where $w=3 \mu \mathrm{m}$ and $b=10 \% \times w$.

direction due to isotropic etching. Fig. 7 displays the error of calculated strain between vertical side wall and nonvertical side wall for width variation. This figure indicates that, for our stain sensor, the calculated strain due to width variation deviates less than $2 \%$. Fig. 8 summarizes the effect of side wall profile factor(n), where $w$ is $3 \mu \mathrm{m}$ and $b$ equals $10 \%$ of beam width. According to this figure, the error drops sharply as $n$ increases. In addition, the deviation of the calculated strain between vertical side wall and nonvertical side wall is less than $1.5 \%$ due to factor $n$ in our case. Moreover, the results in Fig. 8 are independent of $h$, since thickness $(h)$ is eliminated from coefficient $a_{1}$.

\section{Stress Gradient Effect}

Stress gradient may cause a significant out-of-plane deformation of the structure, which is a source of error in the strain sensor measurement. However, this problem can be resolved if the bending effect on the measured displacement is compensated. Gradient stress in general tends to bend released structures up or down. A simple calculation is stated to quantify the error on lateral displacement measurement due to the stress gradient effect. In the proposed strain sensor, residual stress not only elongates the beams but also results 


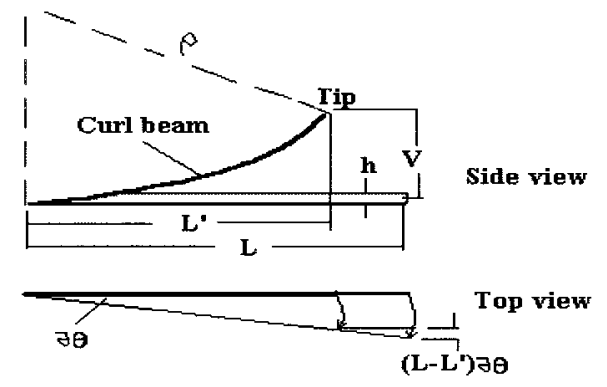

Fig. 9. Error analysis of lateral displacement measurement due to stress gradient effect.

in the lateral deflection of the beams. It is assumed herein that the bending of the beam exists due to gradient stress and its projected length along the actual length $(L)$ of the straight beam is denoted as $L^{\prime}$, as shown in Fig. 9. Thus, the difference of the lateral displacement, $\Delta \delta$, between the free end of the straight beam and the bending beam can be obtained approximately by geometrical configuration

$$
\Delta \delta=\left(L-L^{\prime}\right) \cdot \partial \theta
$$

where $L^{\prime}=(\rho-V) \tan (L / \rho)$ and $V=\varepsilon_{g} \rho . \partial \theta$ denotes a differential angle of lateral deflection, $V$ represents the outof-plane displacement, $\rho$ is the radius-of-curvature, $h$ is the thickness of the beam, and $\varepsilon_{g}$ is the average stress gradient in the film.

In most cases, including our results, $\left(L-L^{\prime}\right) \cdot \partial \theta$ remains extremely small for the minute angle of $\partial \theta$. Hence, error in displacement measurement due to stress gradient effect is negligible. However, excessively warped films would require this compensation.

\section{FABrications, MEASUREMEnt, AND Discussions}

\section{A. Fabrications}

For polysilicon films, a conventional surface-sacrificial layer method is used. The wafers are divided into two groups: one group is put into postannealing, but another is not. For wet oxide films, a bulk micromachining is used. A $2-\mu \mathrm{m} \mathrm{S}_{i} \mathrm{O}_{2}$ film is thermally grown. Finally, the test beams and the extended indicator beam are released by anisotropical time-etching of the Si-substrate [13]. Owing to limitation in our laboratory, we utilize wet etching method to demonstrate the strain sensor's new structure. However, it is possible to fabricate the vertical side wall by other feasible micromachining technique (e.g. Anisotropic Reactive Ion Etching method). Therefore, the primary advantages, i.e., Young's modulus independency, thickness independency, no correction factor and compact structure, which we claim for our device may remain.

\section{B. Measurement}

An optical microscope mounted with a ruler is used to determine the displacement of the tip beam. To measure the displacement, a reference edge is used, otherwise, a vernier gauge can be incorporated into the design. Here we also use the symmetric design, in which two independent strain sensors

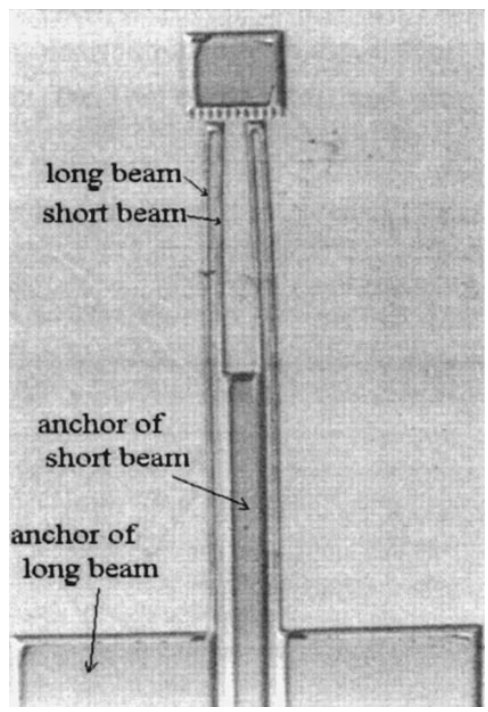

(a)

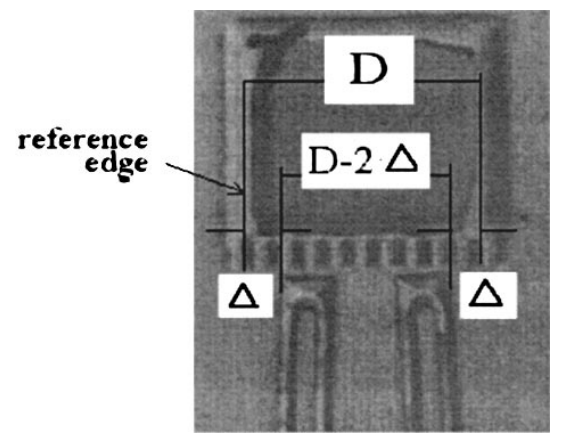

(b)

Fig. 10. The symmetric design of two strain sensors for the displacement measurement of a wet oxide film. (a) Total view. (b) Enlarging measurement view. (Process condition: $1100^{\circ} \mathrm{C}, \mathrm{H}_{2}=25 \mathrm{sccm}, \mathrm{O}_{2}=15 \mathrm{sccm}, 10 \mathrm{~h}$. Dimensions: long beam length $=600 \mu \mathrm{m}$, short beam length $=290 u \mathrm{~m}$, gap $=6.8 \mu \mathrm{m}$, width $=3.5 \mu \mathrm{m}$. Measured displacement $\Delta=8.4 \mu \mathrm{m}$, residual strain $=-1290 \mu \varepsilon$ [residual stress $=-90 \mathrm{MPa}$, where Young's modulus is $70 \mathrm{GPa})$ ].

are constructed symmetrically. In this manner, the double displacement, $2 \Delta$, can be obtained by taking the difference of the distance between two tip beams, as shown in Fig. 10.

Figs. 11 and 12 display the displacements of the tip beam versus different short beam lengths for a wet oxide film and a LPCVD polysilicon film, respectively. The strains calibrated from these strain sensors are -1320 $\mu \varepsilon,-1350 \mu \varepsilon$, and $-1400 \mu \varepsilon$ for the wet oxide film, and are $-1250 \mu \varepsilon,-1200 \mu \varepsilon$, and $-1270 \mu \varepsilon$ for the polysilicon film. The maximum differences are within 80 and $70 \mu \varepsilon$ for the oxide film and the polysilicon film, respectively. The variations in calibrated strains may be attributed to the nonuniform distribution of residual stress in overall film on the wafer. The average calibrated stress in this wet oxide film is about $94 \mathrm{MPa}$ (compressive). The average calibrated stress in the undoped LPCVD polysilicon film without post annealing is about $200 \mathrm{MPa}$ (compressive), and is less than $30 \mathrm{MPa}$ (compressive) after $1-\mathrm{h}$ annealing. In this study, we also fabricate other strain sensors on the same chip, as shown in Fig. 13. Table II lists the calculated strain and measured 


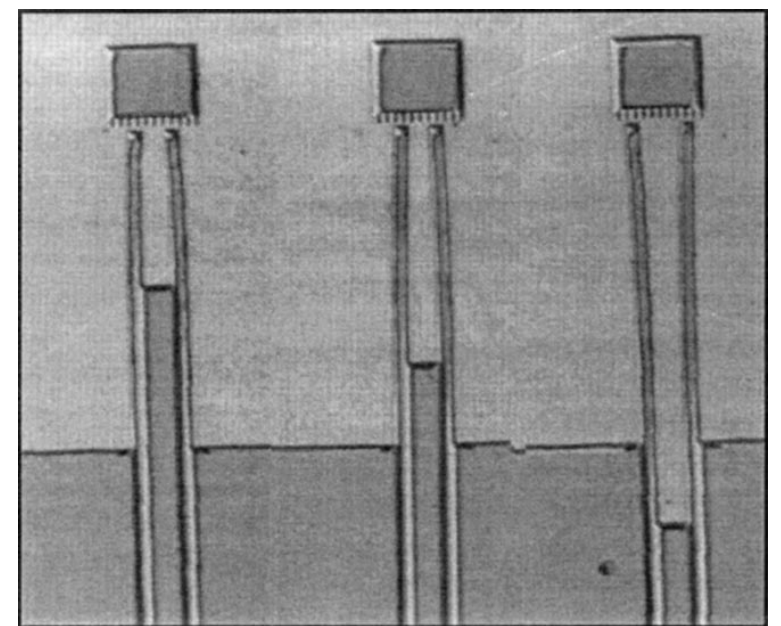

Fig. 11. Different displacements of the tip beam versus variations of the short beam lengths under compressive strain. (Test film: Wet oxide, $1100^{\circ} \mathrm{C}$, $\mathrm{H}_{2}=25 \mathrm{sccm}, \mathrm{O}_{2}=15 \mathrm{sccm}, 10$-h-long beam length $=410 \mu \mathrm{m}$, short beam length $=190 \mu \mathrm{m}, 295 \mu \mathrm{m}, 490 \mu \mathrm{m}$, gap $=6.8 \mu \mathrm{m}$, width $=3.5 \mu \mathrm{m}$, residual strain $=-1320 \mu \varepsilon,-1350 \mu \varepsilon,-1400 \mu \varepsilon$.)

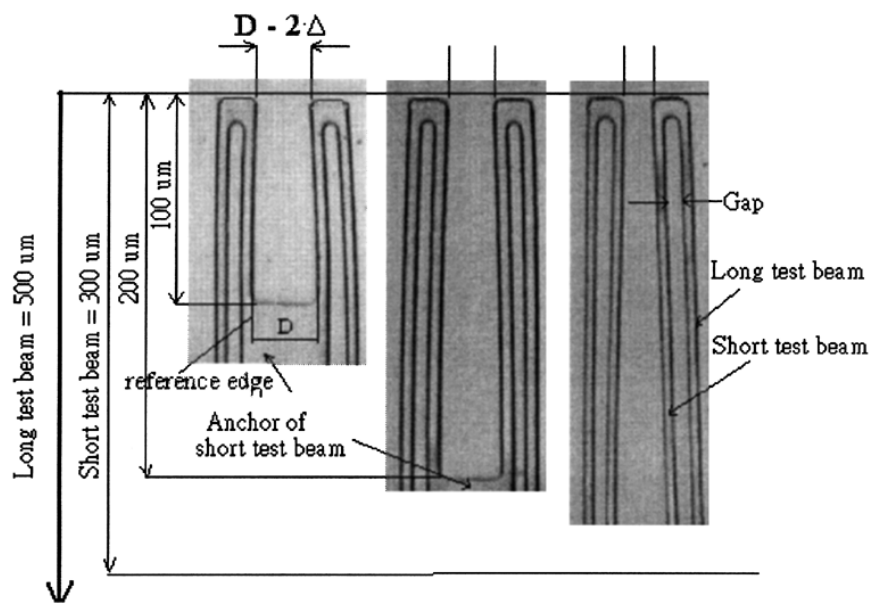

Fig. 12. Different displacements of the tip beam versus variations of the short beam lengths under compressive strain. (Test film: LPCVD Polysilicon, $620^{\circ} \mathrm{C}, 100$ mTorr, $\mathrm{S}_{i} \mathrm{H}_{4}=24 \mathrm{sccm}$, no annealing, undoped. Dimensions: gap $=8.5 \mu \mathrm{m}$, width $=5.5 \mu \mathrm{m}$, residual strain $=-1250 \mu \varepsilon,-1200 \mu \varepsilon,-1270 \mu \varepsilon$.)

displacement of each strain sensor. This feature demonstrates the high reliability of our strain sensors.

\section{Discussions}

It is recommended to make the sacrificial layer thicker to avoid the sticking problem for surface micromachining structures. One potential source of error in the strain measurements is the nonvertical side walls of test beams owing to etching isotropy. However, Fig. 14 indicates that the side wall of the structure proposed herein is nearly vertical, despite the fact that we use wet etching, which can contribute to the deeper undercut during etching beams. Even the side walls generally have $5-10 \%$ width variation in the vertical direction due to isotropic etching, the error of the calculated strain based on assumption of vertical side walls will be less than $2 \%$ for our stain sensor. Reactive ion anisotropic etching (RIAE) process
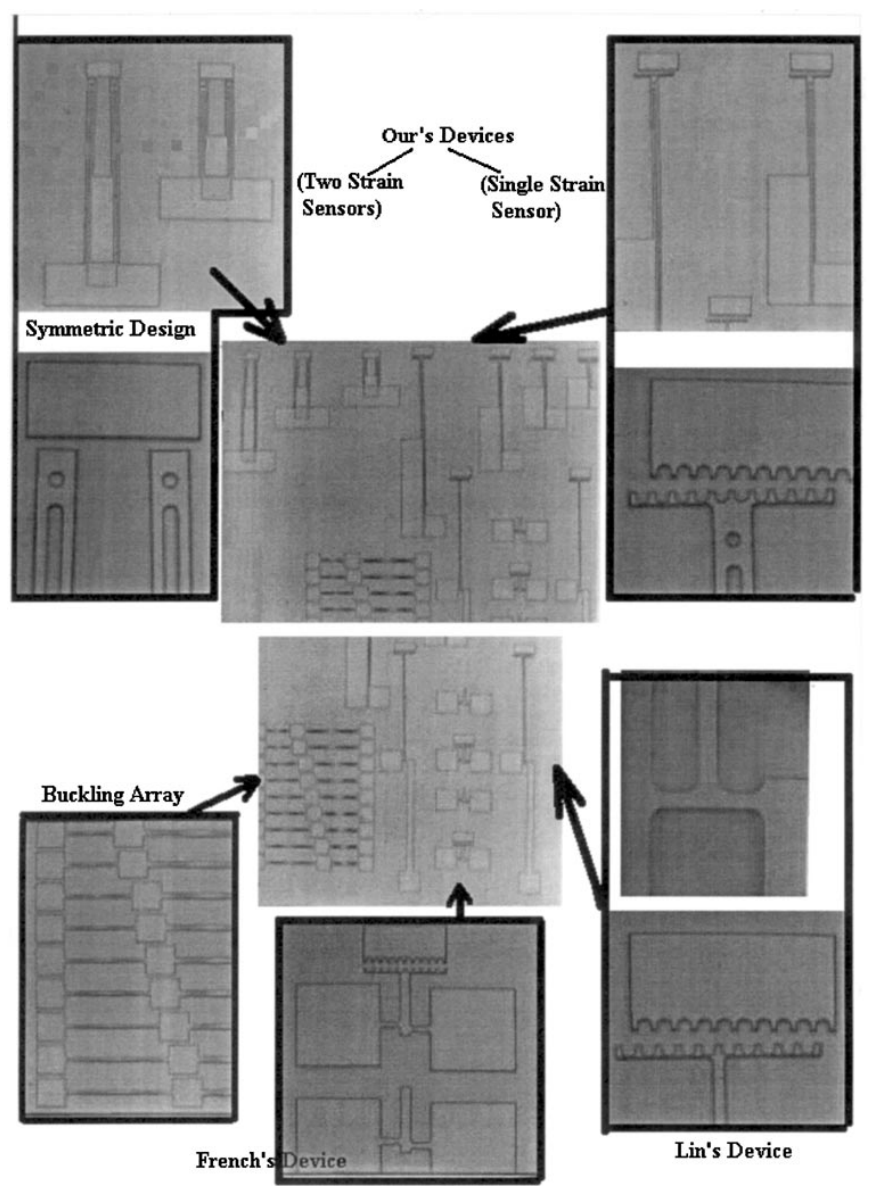

Fig. 13. Comparison of our strain sensors with other strain sensors [1], [7], [9] on the same chip.

TABLE II

The Calculated Strain and Measured Displacement of Our Strain Sensor and Other Strain Sensors on the Same Chip

\begin{tabular}{|c|c|c|c|}
\hline Products & $\mathbf{M}_{\mathbf{p}}$ & $\mathbf{M}_{\mathbf{F}}$ & $\mathbf{M}_{\mathbf{M}}$ \\
\hline $\mathbf{M}_{\mathrm{uI}}$ & $\left(1 / 3 \cdot \mathrm{S}^{3}+\mathrm{S}^{2} \cdot \mathrm{L}_{2}\right) \mathrm{P}$ & $\begin{array}{l}\left(1 / 2 \cdot \mathrm{S}^{2} \cdot \mathrm{L}_{1}+\mathrm{S} \cdot \mathrm{L}_{1} \cdot \mathrm{L}_{2}\right. \\
\left.1 / 2 \cdot \mathrm{S} \cdot \mathrm{L}_{2}{ }^{2}\right) \mathrm{F}\end{array}$ & $-\left(1 / 2 \cdot \mathrm{S}^{2}+\mathrm{S} \cdot \mathrm{L}_{2}\right) \mathrm{M}$ \\
\hline $\mathbf{M}_{\mathbf{u} 2}$ & $\begin{array}{l}\left(1 / 2 \cdot \mathrm{S}^{2} \cdot \mathrm{L}_{1}+\mathrm{S} \cdot \mathrm{I}_{1} \cdot \mathrm{L}_{2}-\right. \\
\left.1 / 2 \cdot \mathrm{S} \cdot \mathrm{L}_{2}{ }^{2}\right) \mathrm{P}\end{array}$ & $\begin{array}{l}\left(1 / 3 \cdot \mathrm{L}_{1}{ }^{3}+\mathrm{L}_{2} \cdot \mathrm{L}_{1}{ }^{2}-\mathrm{L}_{1} \cdot \mathrm{L}_{2}{ }^{2}+\right. \\
\left.1 / 3 \cdot \mathrm{L}_{2}{ }^{3}+\mathrm{S} \cdot \mathrm{L}_{1}{ }^{2}\right) \mathrm{F}\end{array}$ & $\begin{array}{l}\left(1 / 2 \cdot \mathrm{L}_{1}{ }^{2}+\mathrm{L}_{1} \cdot \mathrm{L}_{2}\right. \\
\left.1 / 2 \cdot \mathrm{L}_{2}{ }^{2}+\mathrm{S} \cdot \mathrm{L}_{1}\right) \mathrm{M}\end{array}$ \\
\hline $\mathbf{M}_{\mathbf{u} 3}$ & $\left(1 / 2 \cdot \mathrm{S}^{2}+\mathrm{S} \cdot \mathrm{L}_{2}\right) \mathrm{P}$ & $\begin{array}{l}\left(1 / 2 \cdot \mathrm{L}_{1}{ }^{2}+\mathrm{L}_{1} \cdot \mathrm{L}_{2}-1 / 2 \cdot \mathrm{L}_{2}{ }^{2}\right. \\
\left.\mathrm{S} \cdot \mathrm{L}_{1}\right) \mathrm{F}\end{array}$ & $\left(L_{1}+L_{2}+S\right) M$ \\
\hline $\mathbf{M}_{\mathrm{u} 4}$ & $\left(\mathrm{~S} \cdot \mathrm{L}_{2}+1 / 2 \cdot \mathrm{S} \cdot \mathrm{L}_{2}{ }^{2}\right) \mathrm{P}$ & $\left(1 / 2 \cdot \mathrm{L}_{1} \cdot \mathrm{I}_{2}{ }^{2}-1 / 3 \cdot \mathrm{L}_{2}{ }^{3}\right) \mathrm{F}$ & $\left(1 / 2 \cdot \mathrm{L}_{2}^{2}\right) \mathrm{M}$ \\
\hline
\end{tabular}

can fabricate structures with vertical side walls, however, this technique is currently unavailable in our laboratory. This also accounts for why the optimal gap (small gap) distance of the strain sensor can not be obtained herein. Another possible source of error is nonuniform residual strain distribution of the film over the wafer. Moreover, experimental results demonstrates that the strain sensors fabricated by surface or bulk micromachining techniques are highly promising for different materials.

\section{CONCLUSION}

This work presents a new compact structure of strain sensors for both tensile and compressive strain measurements. The 


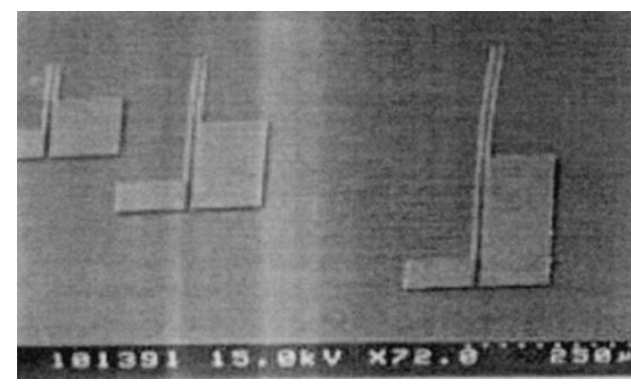

(a)

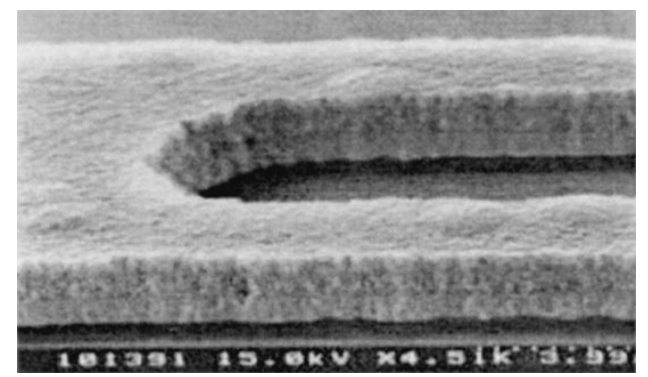

(b)

Fig. 14. The SEM micrographs of the side wall condition of the strain sensor.

analytical model of the strain sensor is free from correction factor. Moreover, the sensor's accuracy is significantly enhanced because the displacement is independent of both Young's modulus and the thickness of the film. Significant factors such as buckling criteria, side wall effect, and stress gradient effect are also thoroughly studied to understand the implicit limitations of the strain sensors. Moreover, an analytical model is derived to relate the measured displacement to the residual strain, thereby optimizing the microstructure and ultimately improving the measured displacement by altering the geometrical dimensions become possible.

\section{APPENDIX A}

By unit-load methods, three constitutive equations are existed for the frame structure in Fig. 2(c)

$$
\begin{aligned}
\delta & =\int M_{u 1} \cdot\left(M_{p}+M_{F}+M_{M}\right) / E \cdot I d x \\
0 & =\int M_{u 2} \cdot\left(M_{p}+M_{F}+M_{M}\right) / E \cdot I d x \\
0 & =\int M_{u 3} \cdot\left(M_{p}+M_{F}+M_{M}\right) / E \cdot I d x
\end{aligned}
$$

where $M_{u 1}, M_{u 2}$, and $M_{u 3}$ denote the moments along the structure generated by the dummy unit loads, respectively. In addition, $M_{p}$ presents the moment generated by the axial force $P, M_{F}$ is the moment generated by the transverse force $F$, and $M_{M}$ denotes the moment generated by the bending moment $M$. Table III lists the products of $M_{u 1}, M_{u 2}$, and $M_{u 3}$ by $M_{p}, M_{F}$, and $M_{M}$. Where $\delta$ represents the axial elongation difference of two-test beams, $E$ denotes the Young's Modulus, and $I$ is the moment of inertia of two beams about $z$ axis. By integrating (16)-(18) and combining (2), (3)-(5) are derived. Therefore, by solving these three simultaneous equations, the values of axial force $P$, transverse force $F$, and bending
TABLE III

The Products of $M_{u 1}, M_{u 2}, M_{u 3}$, AND $M_{u 4}$ By $M_{p}, M_{F}$, AND $M_{M}$

\begin{tabular}{l|l|c|l}
\hline $\begin{array}{l}\text { Strain } \\
\text { sensor }\end{array}$ & \multicolumn{1}{|c|}{ Dimensions } & Measured displacement & $\begin{array}{l}\text { Calculated } \\
\text { strain }\end{array}$ \\
\hline ours & $\begin{array}{l}\mathrm{L} 1=701.3 \mu \mathrm{m}, \quad \mathrm{L} 2=349.8 \mu \mathrm{m}, \\
\mathrm{S}=6.6 \mu \mathrm{m}, \mathrm{w}=3.5 \mu \mathrm{m}, \mathrm{h}=2 \mu \mathrm{m}\end{array}$ & $10.1 \mu \mathrm{m}$ & $1110 \mu$ \\
\cline { 2 - 4 } & $\begin{array}{l}\mathrm{L} 1=431.2 \mu \mathrm{m}, \quad \mathrm{L} 2=214.5 \mu \mathrm{m}, \\
\mathrm{S}=6.4 \mu \mathrm{m}, \mathrm{w}=3.7 \mu \mathrm{m}, \mathrm{h}=2 \mu \mathrm{m}\end{array}$ & $3.9 \mu \mathrm{m}$ & $1140 \mu$ \\
\hline French's & $\begin{array}{l}\mathrm{O}=5.5 \mu \mathrm{m}, \quad \mathrm{Lc}=59.1 \mu \mathrm{m}, \\
\mathrm{k}=3.8 \mu \mathrm{m}\end{array}$ & $0.9 \mu \mathrm{m}$ & $1120 \mu$ \\
\hline Lin's & $\begin{array}{l}\mathrm{LA}=\mathrm{LB}=20.2 \mu \mathrm{m}, \mathrm{h}=2 \mu \mathrm{m} \\
\mathrm{W}_{\mathrm{s}}=2.9 \mu \mathrm{m}, \quad \quad \mathrm{Wt}=32 \mu \mathrm{m} \\
\mathrm{W}=4.5 \mu \mathrm{m}, \mathrm{h}=2 \mu \mathrm{m}, \mathrm{Ls}=50.5 \mu \mathrm{m} \\
\mathrm{L}=520.2 \mu \mathrm{m}, \quad \mathrm{Li}=520 \mu \mathrm{m}\end{array}$ & $8.9 \mu \mathrm{m}$ & $1118 \mu$ \\
\hline
\end{tabular}

moment $M$ can be found

$$
\begin{aligned}
p & =\frac{z \cdot\left|\begin{array}{ll}
b_{2} & c_{2} \\
b_{3} & c_{3}
\end{array}\right|}{\left|\begin{array}{lll}
a_{1} & b_{1} & c_{1} \\
a_{2} & b_{2} & c_{2} \\
a_{3} & b_{3} & c_{3}
\end{array}\right|} \\
F & =\frac{-z \cdot\left|\begin{array}{ll}
a_{2} & c_{2} \\
a_{3} & c_{3}
\end{array}\right|}{\left|\begin{array}{lll}
a_{1} & b_{1} & c_{1} \\
a_{2} & b_{2} & c_{2} \\
a_{3} & b_{3} & c_{3}
\end{array}\right|} \\
M & =\frac{z \cdot\left|\begin{array}{lll}
a_{2} & b_{2} \\
a_{3} & b_{3}
\end{array}\right|}{\left|\begin{array}{lll}
a_{1} & b_{1} & c_{1} \\
a_{2} & b_{2} & c_{3} \\
a_{3} & b_{3} & c_{3}
\end{array}\right|}
\end{aligned}
$$

where $z=E \cdot I \cdot \varepsilon \cdot\left(L_{1}-L_{2}\right)$. Subsequently, to determine the displacement of the tip point $O$, a dummy unit force at tip point $O$ in the deflection direction is applied, as shown in Fig. 2(c) which is assumed to be under compressive state. Then, by following a similar derivation as above, the displacement of the point $O, \Delta$, can be derived from the equation below

$$
\Delta=\int M_{u 4} \cdot\left(M_{p}+M_{F}+M_{M}\right) / E \cdot I d x
$$

where $M_{u 4}$ denotes the moment along the structure generated by the dummy unit force applied at tip point $O$ in the deflection direction. Table III lists the products of $M_{p}, M_{F}$, and $M_{M}$ by $M_{u 4}$. After integrating (22), $\Delta$ is expressed as

$$
\begin{aligned}
\Delta= & {\left[\left(1 / 2 \cdot S \cdot L_{2}^{2}\right) \cdot P+\left(1 / 2 \cdot L_{1} \cdot L_{2}^{2}-1 / 3 \cdot L_{2}^{3}\right) \cdot F\right.} \\
& \left.+\left(1 / 2 \cdot L_{2}^{2}\right) \cdot M\right] / E I .
\end{aligned}
$$

Then, by substituting (19)-(21) into (23) and rearranging (23), $\varepsilon$ can be expressed as a function of $\Delta$, which is presented in (7) and (8).

\section{ACKNOWLEDGMENT}

The staffs of the Semiconductor Research Center at National Chiao Tung University are appreciated, along with Dr. L. Lin for providing the testing equipment. 


\section{REFERENCES}

[1] H. Guckel, T. Randazzo, and D. W. Burns, "A simple technique for the determination of mechanical strain in thin films with applications to polysilicon,” J. Appl. Phys., vol. 57, no. 5, pp. 1671-1675, Mar. 1, 1985.

[2] H. Guckel, D. W. Burns, and C. C. G. Visser et al., "Fine-grained polysilicon films with built-in tensile strain," IEEE Trans. Electron Devices, vol. 35, no. 6, pp. 800-801, 1988.

[3] H. Guckel, D. W. Burns, and C. Rutigliano et al., "Diagnostic microstructures for the measurement of intrinsic strain," in Thin Films, J. Micromech. Microeng., vol. 2, pp. 86-95, 1992.

[4] R. Mutikainen and M. Orpana, "Slicon surface micromachined structures for the stress measurement of thin films," in Mat. Res. Soc. Symp. Proc., 1993, vol. 308, pp. 153-158.

[5] M. G. Allen, M. Mehregany, R. Howe, and S. Senturia, "Microfabricated structures for the in situ measurement of residual stress, Young's modulus and ultimate strain of thin films," Appl. Phys. Lett., vol. 51, pp. 241-243, 1987.

[6] M. Mehregany, R. Howe, and S. Senturia, "Novel Microstructures for the in situ measurement of the mechanical properties of thin films," $J$. Appl. Phys., vol. 62, no. 9, pp. 3579-3584, 1987.

[7] B. P. Van Drieenhuizen, J. F. L. Goosen, P. J. French, and R. F. Wolffenbuttel, "Comparison of techniques for measuring both compressive and tensile stress in thin films," Sensors and Actuators A, vols. 37-38, pp. 756-765, 1993.

[8] P. J. French, B. P. Van Drieenhuizen, D. Poenar, J. F. L. Goosen, R. Mallee, P. M. Sarro, and R. F. Wolffenbuttel, "The development of a low-stress polysilicon process compatible with standard device processing," IEEE J. Microelectromech. Syst., vol. 5, pp. 187-195, 1996.

[9] L. Lin, A. P. Pisano, and R. T. Howe, "A micro strain gauge with mechanical amplifier," IEEE J. Microelectromech. Syst., vol. 6, pp. 313-321, Dec. 1997

[10] Y. B. Gianchandani and K. Najafi, "Bent-beam strain sensors," IEEE J. Microelectromech. Syst., vol. 5, pp. 52-58, Mar. 1996.

[11] S. P. Timoshenko and J. M. Gere, Mechanics of Materials, 3rd ed. Boston: PWS, 1990, pp. 632-647.
[12] H. Matoba, T. Ishikawa, C. J. Kim, and R. S. Muller, "A bistable snapping microactuator," in Proc. IEEE Micro Electro Mechanical Systems Workshop (MEMS'94), Oiso, Japan, 1994, pp. 45-50.

[13] W.-s. Choi and J. G. Smits, "A method to etch undoped silicon cantilever beams," IEEE J. Microelectromech. Syst., vol. 2, pp. 82-86, June 1993.

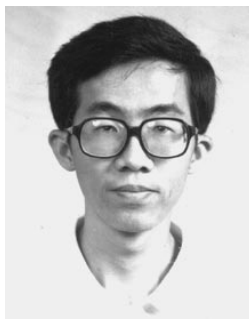

Chi Shiang Pan received the B.S. and Ph.D degrees in mechanical engineering from National Chiao Tung University in 1984 and 1998, respectively, and the M.S. degree in mechanical engineering from National Sun Yi Xian University, Taiwan, R.O.C., in 1989.

$\mathrm{He}$ is currently an Associate Professor in the Department of Mechanical Engineering in National Chin Yi Institute of Technology, where his research interests are in microelectromechanical systems, including design, modeling and fabrication of microstructures, microsensors, and microactuators.

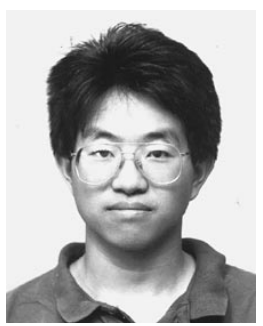

Wensyang Hsu received the B.S. degree in mechanical engineering from National Chiao Tung University, Taiwan, in 1985, and the M.S. and $\mathrm{Ph} . \mathrm{D}$. degrees in mechanical engineering from the University of California at Berkeley in 1989 and 1992, respectively.

Since 1992, he has been an Associate Professor in the Department of Mechanical Engineering, National Chiao Tung University, Taiwan. His research interests are in microelectromechanical systems, including design, modeling, and fabrication of microstructures, microsensors, and microactuators. 